Article

\title{
Temporal Evolution of Regional Drought Detected from GRACE TWSA and CCI SM in Yunnan Province, China
}

\author{
Siyu Ma ${ }^{1,2}$, Qianxin Wu ${ }^{1,2}$, Jie Wang ${ }^{3}$ and Shiqiang Zhang ${ }^{1,2, *}$ (i) \\ 1 Shaanxi Key Laboratory of Earth Surface System and Environmental Carrying Capacity, Northwest \\ University, Xi'an 710127, China; maasiyu@163.com (S.M.); 201620782@stumail.nwu.edu.cn (Q.W.) \\ 2 College of Urban and Environmental Science, Northwest University, Xi'an 710127, China \\ 3 Yunnan Institute of Water Resources and Hydropower Research, Kunming 650221, China; wangjie@lzb.ac.cn \\ * Correspondence: zhangsq@lzb.ac.cn
}

Received: 12 August 2017; Accepted: 2 November 2017; Published: 4 November 2017

\begin{abstract}
Droughts are one of the most devastating natural disasters, which impose increasing risks to humanity and the environment in the 21st century. The recent and continuous drought in China has led to detrimental effects on the local environment and societies in Yunnan Province, thus there is an urgent need to monitor the spatial and temporal evolution of the drought. The characteristics of the spatial distribution of drought processes and the impact of droughts on soil moisture and water storage remains unclear. In this study, the direction, magnitude, start time, and duration of droughts were investigated, based on Total Water Storage Anomalies (TWSA) of Gravity Recovery and Climate Experiment (GRACE), Climate Change Initiative Soil Moisture (CCI SM), and observed precipitation data. The spatial patterns of TWSA trends at each time duration segment suggest that the evolution of drought processes is very complex, and can be clustered into three zones. The spatial distribution of TWSA revealed that the drought status lasted more than one year longer in the north and east parts compared to other parts of Yunnan Province. Water losses occurred in the south part, while water gains were found in the central, north, and east parts of Yunnan Province, from 2002 to 2014, indicating a higher possibility of droughts in the south part in the future. Both de-seasonalized TWSA and CCI SM effectively captured the serious drought from 2009 to 2010 in Yunnan, and their spatial patterns were found to be consistent. The drought detected from CCI SMA had a one-month lag and TWSA had a two-month lag, in comparison to the meteorological drought from precipitation data, which indicates that the drought data derived from CCI SMA and TWSA are better able to represent the impact of droughts, particularly on agriculture. The contribution of surface SM changes in TWSA was determined to be about $41.94 \%$, suggesting that variations in soil moisture only explain less than half of the total water storage change. GRACE observations and CCI SM can be used as important indicators of the spatial distribution of the drought process and its impact on the environment and local communities, which will improve the management of water resources and early detection and monitoring of droughts.
\end{abstract}

Keywords: drought; evolution stage; GRACE; CCI SM; Yunnan Province

\section{Introduction}

Droughts are one of the most devastating natural disasters, which have affected more than half the world, resulting in an average annual loss of US $\$ 60$ billion to $\$ 80$ billion [1]. Longer, more severe, and more frequent soil moisture droughts have been experienced in 37\% of China, between 1950 and 2006 [2]. With rapid economic development, population growth, and climate change, the number of drought-affected areas could be further increased, and drought severity would be more aggravated, 
due to the shortage of water [3]. In addition, climate change can indeed alter the probability of extreme hydrological events, such as flooding and droughts [4], which will be more pronounced in drylands, where about $44 \%$ more warming occurs, compared to humid lands, when global climates increase by $2{ }^{\circ} \mathrm{C}$ [5]. In addition, the amount of dryland areas are projected to increase by $23 \%$ and $11 \%$, relative to the 1961-1990 baseline, under the representative concentration pathways (RCPs), RCP8.5 and RCP4.5, respectively [6].

It is pertinent to note that severe droughts usually occurred in Southern China, especially in the southwest region [7-9], which is humid, with relatively heavy precipitation. These droughts have greatly impacted local societies and environment, where there is a developing economy and higher population. For example, a severe and sustained drought hit Yunnan Province in southwest China, from autumn 2009 until spring 2010 [10,11], resulting in \$2.5 billion of agricultural damage and a shortage of drinking water for about 9.65 million people [7]. The accurate monitoring and prediction of droughts are very important to protect socio-economic stability and agriculture.

A drought is a complex phenomenon that is difficult to directly observe, due to high spatial heterogeneity in its occurrence time, development process, and influence range, which is parameterized using a drought index $[12,13]$. There are hundreds of drought indices around the world that are based on specific geographical and temporal ranges [14]. Most drought indices are only affected by observed precipitation, considering that droughts are caused directly by less rainfall, and precipitation data are more readily available, compared to other atmospheric variables. For example, the SPI (Standard Precipitation Index) has been used as an early warning for droughts in Ohio, USA [15,16].

A drought is essentially a water-deficit phenomenon caused by insufficient precipitation. During a drought, soil moisture (SM) decreases, along with the continuous evaporation of soil water [17], which directly restricts plant growth. Thus, SM as a parameter has the potential to monitor drought. SM [18] can be monitored through ground observations or remote sensing. The advantages of ground observation are that it is fast and accurate, yet it is difficult to reflect the soil moisture dynamics in a larger area by solely relying on ground observation data, which is influenced by local factors, such as slope, aspect, and land use. Remote sensing can be used to obtain the spatial variations of soil moisture and has the advantages of a wide range, high speed, and low cost. Soil moisture, derived from satellite microwave sensors, has received increasing attention, since microwaves can penetrate into the ground surface to obtain measurements.

Several global satellite-based soil moisture products that contain microwave sensors have been released, which include the Advanced Microwave Scanning Radiometer E for the Earth observing system (AMSR-E) [19], the Advanced Scatterometer (ASCAT) [20,21], the Soil Moisture and Ocean Salinity (SMOS) [22], and the European Space Agency's (ESA) Climate Change Initiative Soil Moisture (CCI SM) product [23-26]. Peng et al. [27] reported that the CCI SM can effectively represent the temporal dynamics of soil moisture in Yunnan, after an evaluation of AMSR-E, ASCAT, SMOS, CCI SM and in situ surface soil moisture data.

Total Water Storage (TWS) is a comprehensive reflection of changes in surface water, groundwater, soil moisture snow water, and biological water [28,29]. Since being launched in March 2002, the Gravity Recovery and Climate Experiment (GRACE) mission has provided TWS Anomalies (TWSA) data, which can be used for analyzing global or regional TWS. Many studies [30-33] have successfully applied TWS to drought detection. Further, the spatial patterns and temporal dynamics of a large drought in Australia were identified from GRACE data [34].

These studies suggest that CCI SM and GRACE TWSA have the potential to detect drought from soil moisture and regional water storage changes. However, previous studies paid little attention to the quantitative assessment of drought processes using total water storage and soil moisture in different spatial and temporal scales. This study was conducted based on the following objectives: (1) to determine whether TWS can effectively detect the spatial and temporal evolution of droughts; and (2) to investigate the differences between drought reflected by CCI SM and drought reflected by GRACE TWSA. 


\section{Data and Methods}

\subsection{Study Area}

Yunnan Province is located in southwest China $\left(21^{\circ} 8^{\prime}-29^{\circ} 15^{\prime} \mathrm{N}, 97^{\circ} 31^{\prime}-106^{\circ} 11^{\prime} \mathrm{E}\right)$ and has a total area of about $394,000 \mathrm{~km}^{2}$. This province is situated in a mountainous area with a decreasing elevation from the northwest to the southeast and has an average altitude of 1980 MASL (meters above sea level). This region also has a subtropical climate, where winter and summer are controlled and influenced by different atmospheric circulations [35]. The temporal and spatial distribution of precipitation in this region is varied and is affected by the barrier effect of the Tibetan Plateau (Figure 1). Between 1960 and 2013, the largest and lowest recorded annual precipitations were $1291 \mathrm{~mm}$ in 2001 and $909 \mathrm{~mm}$ in 2009 [36].
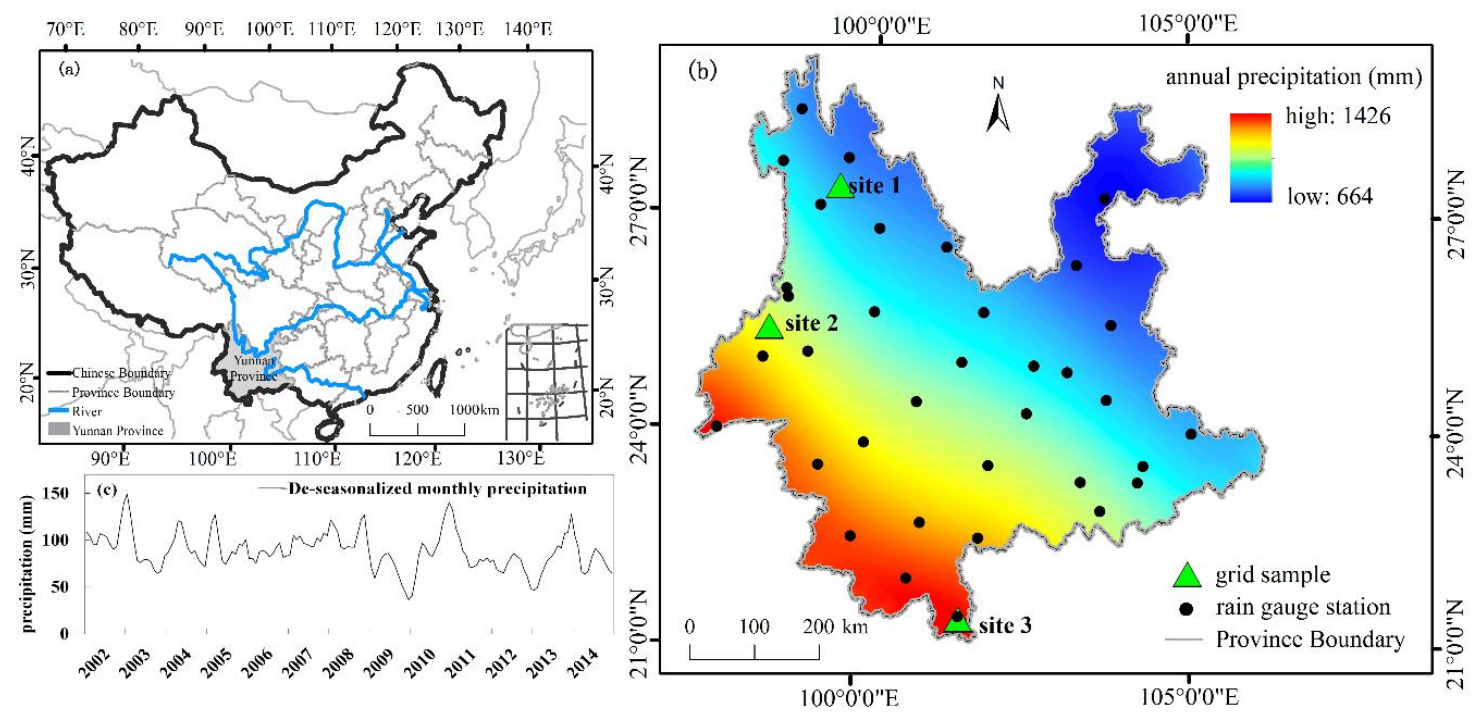

Figure 1. (a) Location map; (b) average annual precipitation map; and (c) time series of de-seasonalized monthly precipitation from 2002 to 2014 in Yunnan Province; triangle symbols in (b) represent three samples for the analysis of regional Total Water Storage Anomalies (TWSA) variations.

\subsection{Data}

\subsubsection{GRACE Total Water Storage}

Detailed measurements of the Earth's gravitation field, obtained by GRACE, have revealed information about gravity and the Earth's natural systems. Deriving month-to-month gravity field variations from GRACE observations requires a complex inversion of the changing observations between the two formation-flying GRACE spacecrafts, combined with precise orbit determination, via a Global Position System (GPS), and various corrections for spacecraft accelerations that are not related to gravitational changes. The GRACE TWSA data were pre-processed to remove the signal by filtering and truncation; this was generated with a spatial resolution of $1^{\circ}$ and temporal resolution of 1 month with units in $\mathrm{cm}[37,38]$. Many parameter choices and solution strategies have been explored by the Jet Propulsion Laboratory (JPL), the Center for Space Research at University of Texas, Austin (CSR) and the GeoforschungsZentrum Potsdam (GFZ) [39]. In order to minimize the uncertainty of GRACE data in this study, the average and standard deviations of the TWS from JPL, CSR, and GFZ were used.

Monthly GRACE TWSA were calculated from the differences between TWS in the current month and the baseline average of TWS from January 2004 to December 2009. The average TWSA was calculated for the period from April 2002 to November 2014, for a total of 140 months. Data was not collected for 12 out of the 152 months (June and July 2002, June 2003, January and June 2011, May and October 2012, March, August, and September 2013, and February and July 2014). To make similar 
comparisons to those made between TWS and CCI SM, TWSA was recalculated as the surface mass deviation for each month relative to the baseline average from January 2007 to December 2014.

\subsubsection{SM}

CCI SM was generated within the framework of the ESA's Water Cycle Multimission Observation Strategy and Climate Change Initiative projects, with the objective of producing the most complete and most consistent global land surface soil moisture data record, based on four passive and two active microwave SM products $[23,24]$. The latest version (2.2) of CCI SM is comprised of satellite-based soil moisture data from 1978 to 2014 . CCI SM has three types of products-active, passive, and combined products-that are based on the former two datasets [26]. Herein, we used the combined CCI SM data.

CCI SM products (unit: $\mathrm{m}^{3} \cdot \mathrm{m}^{-3}$ ) were provided in the NetCDF-4 format, with a spatial resolution of $0.25^{\circ}$ and temporal resolution of 1 day. We originally intended to use combined products for the period from 2002 to 2014; however, we found that CCI SM monthly variations were serrated from 2002 to 2006, without a seasonal cycle and regular fluctuations. Therefore, we utilized CCI SM datasets from 2007 to 2014 to make comparisons with TWSA. CCI Soil Moisture Anomalies (CCI SMA) were calculated from the differences between CCI SM in the current month and the baseline average of CCI SM from January 2007 to December 2014.

\subsubsection{Ground-Based Observation Data}

Monthly precipitation data from 35 national rain gauge stations in Yunnan Province during 2002-2014 were downloaded from the National Meteorological Information Center of the China Meteorological Administration (CMA) [40]. In situ soil moisture data from 18 soil moisture observation stations in Yunnan Province during 2008-2012 were obtained from the Yunnan Hydrology and Water Resources Bureau. The soil moisture (unit: $\mathrm{m}^{3} \cdot \mathrm{m}^{-3}$ ) from these stations was measured using frequency domain reflectometry (FDR) sensors at three different depths $(10,20$, and $40 \mathrm{~cm})$.

\subsection{Methods}

\subsubsection{Meteorological Drought}

We used the percentage of precipitation anomalies $(\mathrm{Pa})$ as drought indices for the Yunnan province, in order to define different drought classes: slight drought $(-60<\mathrm{Pa} \leq-40)$, moderate drought $(-80<\mathrm{Pa} \leq-60)$, serious drought $(-95<\mathrm{Pa} \leq-80)$, and extreme drought ( $\mathrm{Pa} \leq-95)$, according to Chinese meteorological standards [41]. Since CCI SM and TWSA lack the approved standards for drought evaluation, for the purposes of comparison, we normalized the anomalies of CCI SM, TWSA, and precipitation data, based on min-max Normalization. The above relative standards were considered to define deferent drought grades of CCI SM and TWSA.

The normalized equation is as follows:

$$
\frac{x_{i}-x_{\min }}{x_{\max }-x_{\min }}=\frac{X_{i}-X_{M I N}}{X_{M A X}-X_{M I N}}
$$

where $x_{\min }, x_{\max }$ are the minimum and maximum values of the $x$ series data, and $X_{M I N}, X_{M A X}$ are the minimum and maximum values of the $X$ series data, respectively.

This equation can make the intervals of two different groups of data consistent.

\subsubsection{Trends and Transition Dates between Different Periods of TWSA}

The complete study period was divided into big dry, big wet, and fluctuation segments [34]. The "big dry" segment referred to arid periods, which had significant reductions of TWSA; "big wet" defined the humid periods, which had significant increases in TWSA; and "fluctuation period" represented periods with no observable trends. The transition dates, defined as the month of the transition from one 
segment to another segment, were calculated following the method proposed by Xie et al. [34], which was successfully used in the analysis of TWSA in Australia.

First, the TWSA time series data was de-seasonalized and smoothed using 'Seasonal Decomposition of Time Series by Census Method I', otherwise known as the ratio-to-moving-average method [42]. We calculated the differences between the adjacent peak and valley of the de-seasonalized and smoothed TWSA, to determine the characteristics of each segment. If the final TWSA was much larger than the initial TWSA at this segment, and their difference was greater than the differences at other segments, the period was defined as "big wet". On the contrary, if the final TWSA was much smaller than the initial TWSA at the segment, and their difference was less than the differences at other segments, the segment was defined as "big dry". We also took a visual inspection for TWSA time series to check whether the trend breaks were reasonable. After defining each segment, the trend of TWSA in the segment was calculated using linear regression, via the ordinary least squares method, and the trend unit was transformed from $\mathrm{cm} /$ month to $\mathrm{cm} /$ year after multiplying by 12 . The total water change was estimated by multiplying the trend by the total months in the segment. The trends and transition dates of each grid were calculated independently in Yunnan Province, and then were used to analyze the evolution process of droughts in this region.

\subsubsection{Correlation between TWSA and CCI SM}

The correlation between TWSA and CCI SM was measured by Pearson's correlation coefficient (r) [43], which was used to determine the score for pair-wise similarity. It ranges from -1 to +1 . An $r$ value is closer to 1 indicates that the positive correlation is stronger, while an $r$ value closer to -1 indicates that the negative correlation is stronger. It is calculated as follows:

$$
r=\frac{\sum_{i=1}^{n}\left(T_{i}-\bar{T}\right)\left(S_{i}-\bar{S}\right)}{\sqrt{\sum_{i=1}^{n}\left(T_{i}-\bar{T}\right)^{2}\left(S_{i}-\bar{S}\right)^{2}}}
$$

where $n$ is the total number of months with both TWSA and CCI SM data; $T$ represents TWSA, $S$ represents CCI SM and $\bar{T}$ and $\bar{S}$ are the average values over $n$ of $T$ and $S$, respectively.

\subsubsection{Contribution of SMA to TWSA}

To examine the contribution of land surface moisture to total water storage change, we calculated it in a very simple manner. First, we calculated the trend and duration of de-seasoned SMA of CCI SM and in situ SM at 10, 20, and $40 \mathrm{~cm}$ depths in one segment, respectively. In the study by Owe et al. [44], it was found that CCI SM can better represent the soil moisture in the top $2 \mathrm{~cm}$ below the surface; thus, we used the change in CCI SM as the soil moisture change for the top $2 \mathrm{~cm}$. We took the in situ SM at 10,20 , and $40 \mathrm{~cm}$ to represent the soil moisture of soil layers with thicknesses of 2-10,10-20, and $20-40 \mathrm{~cm}$, respectively.

The total changes in soil moisture $\left(\Delta_{\text {soil moisture, }}\right)$ in the segment were calculated by multiplying the trend with the duration. The equivalent water thickness of soil moisture change $\left(T_{\text {water }, i}\right)$ was calculated as:

$$
T_{\text {water }, i}=\Delta_{\text {soil moisture }, i} \times T_{\text {soil }, i}
$$

where $i$ is the $i$ th soil layer; and $T_{\text {soil }, i}$ represents the surface thickness of the current soil layer, which was 2, 8, 10, and $20 \mathrm{~cm}$ for the CCI SM and 10, 20, $40 \mathrm{~cm}$ for the in situ SM, respectively.

Finally, we quantified the contribution of SM change to TWSA as:

$$
C \%=\frac{\sum_{i=1}^{4} T_{\text {water }, i}}{T W S A} \times 100 \%
$$




\section{Results}

\subsection{TWSA Trend of Whole Yunnan Province}

The average monthly TWSA of all grids in Yunnan Province from 2002 to 2014 (Figure 2) suggest that TWSA has obvious seasonality, with a maximum value around August, in summer, and a minimum value in April, in spring. The de-seasonalized monthly TWSA can be divided into four segments, including a dry period from April 2002 to August 2006 (Segment 1), followed by a wet period from September 2006 to November 2008 (Segment 2), and the second dry period from December 2008 to March 2010 (Segment 3), and finally a fluctuating period from April 2010 to the end of the study period in November 2014 (Segment 4).

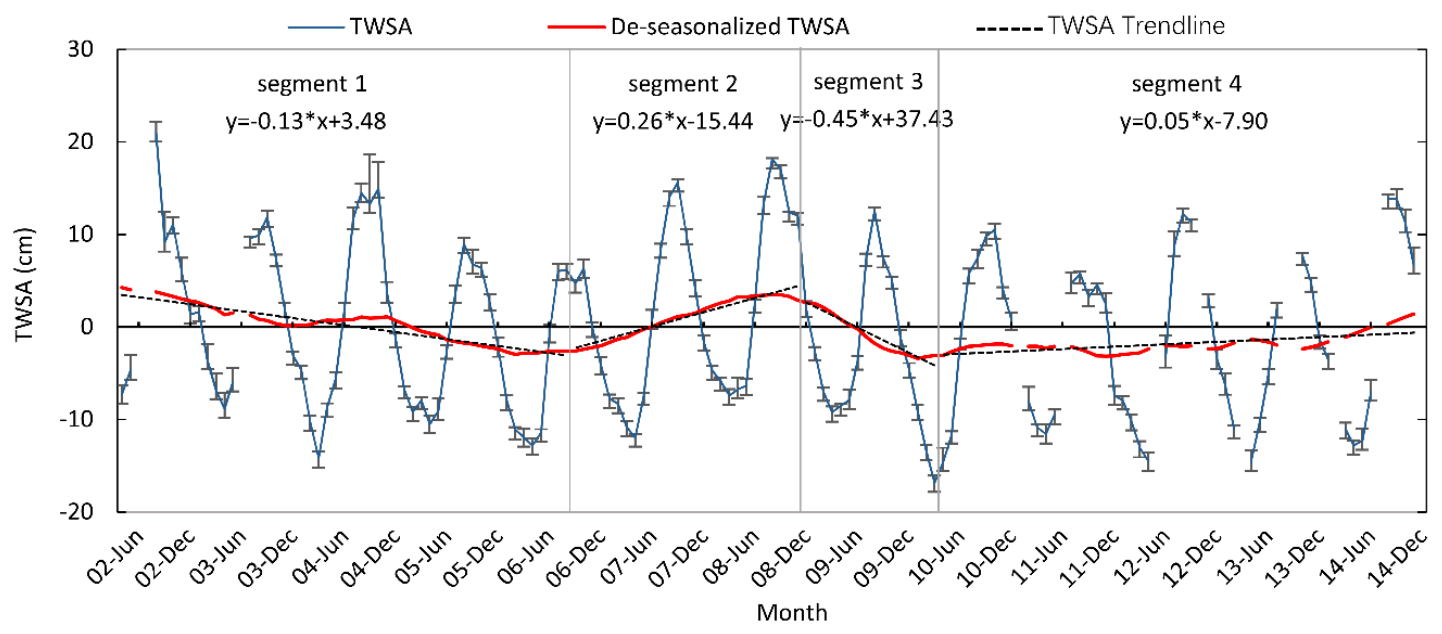

Figure 2. Monthly average Total Water Storage Anomalies of all grids of Yunnan Province from April 2002 to November 2014 (solid blue line). The solid red line is the de-seasonalized and smoothed TWSA. The black dashed lines are the linear trends of the de-seasonalized TWSA during the first big dry period, big wet period, second big dry period and fluctuating period, respectively. The error bars indicate the standard deviations among the three Gravity Recovery and Climate Experiment (GRACE) datasets, provided by the Center for Space Research at University of Texas, Austin (CSR), Jet Propulsion Laboratory (JPL) and GeoforschungsZentrum Potsdam (GFZ). The month without data is vacant.

Segment 1 is characterized as big dry, in which the TWSA significantly ( $p=0.05)$ decreased by $1.60 \mathrm{~cm}$ /year. Segment 2 is characterized as big wet, in which the total water storage rebounded and the TWSA significantly $(p=0.05)$ increased, from $-2.38 \mathrm{~cm}$ to $4.42 \mathrm{~cm}$, at a rate of $3.14 \mathrm{~cm} /$ year. Segment 3 is characterized as big dry, in which the TWSA had a significantly $(p=0.05)$ higher decline rate $(5.43 \mathrm{~cm}$ /year). In Segment 4, TWSA was nearly stable-TWSA fluctuated between $-3.07 \mathrm{~cm}$ to $-0.61 \mathrm{~cm}$ over more than four years-and had a significant $(p=0.05)$ slightly increasing trend of $0.63 \mathrm{~cm} /$ year.

\subsection{TWSA Trends from Three Typical Sites}

To examine if TWSA has a consistent trend and transition date in all grids in Yunnan Province, we selected three grids located in the north (site 1), northwest (site 2), and south parts (site 3) (triangle symbols in Figure 1), to analyze the TWSA series at each grid. In Figure 3, the four segments are clear in the three grids; however, there are large differences in the trend in each segment and the transition date between adjacent segments. For example, the TWSA in site 1 had a longer period of Segment 3 , with a smaller rate of reduction (Figure 3a). The TWSA in site 2 had a slight decrease $(p=0.05)$ in Segment 4 (Figure 3b), and the TWSA in site 3 had an earlier onset of Segment 2 and a higher increase rate in Segment 4 (Figure 3c). These results indicate that the water storage change probably has a large 
spatial difference, and the onset dates of arid and wet periods are different in various parts of Yunnan Provence. Thus, we classified the whole Yunnan Province into south, northwest, and north zones.
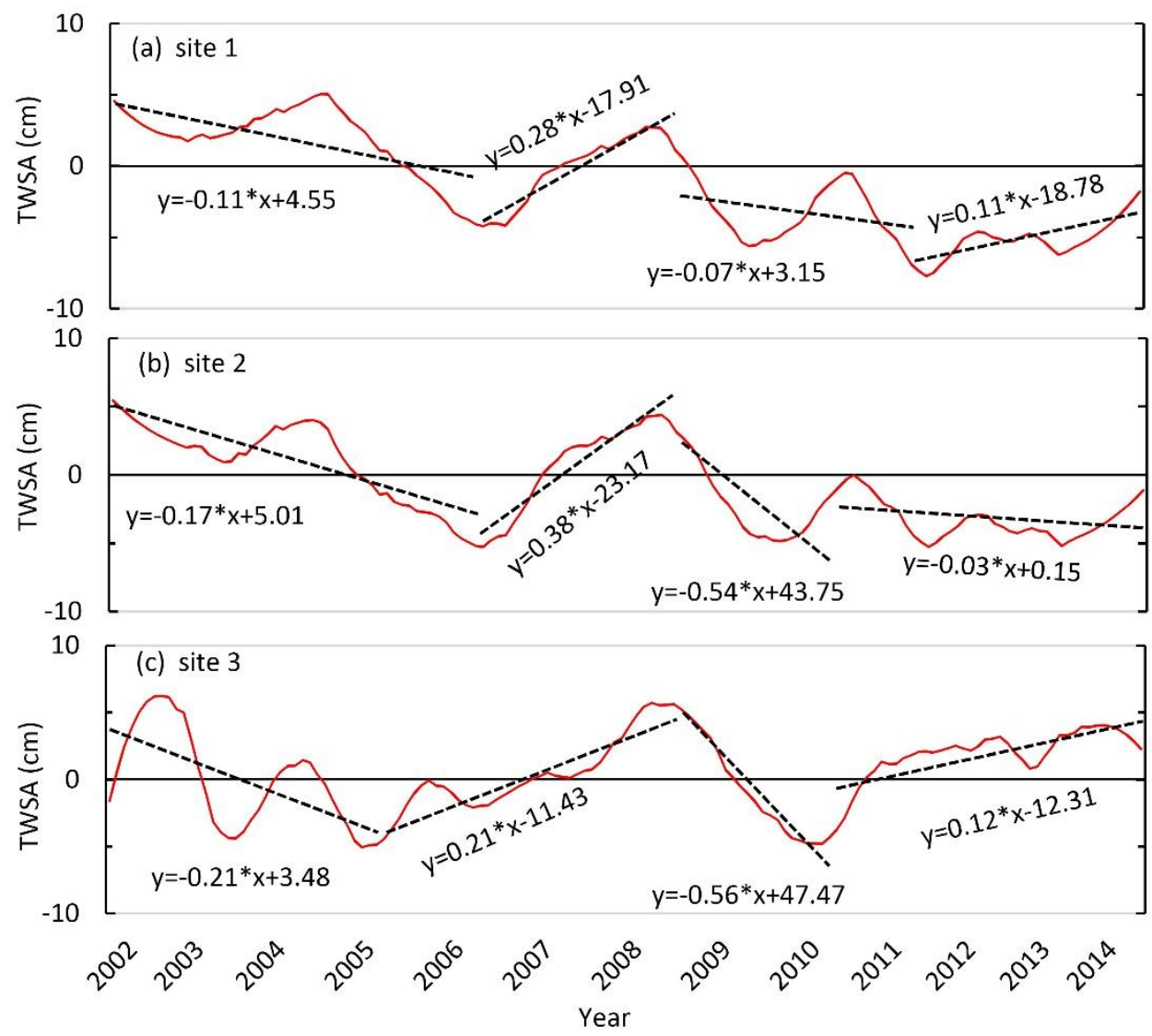

Figure 3. Variations of de-seasonalized Total Water Storage Anomalies in the three grids located in north (site 1), northwest (site 2) and south (site 3) parts of Yunnan Province. The red solid lines are de-seasonalized Total Water Storage Anomalies. The black dashed lines represent the linear trends of de-seasonalized TWSA during four segments. The $\mathrm{x}$ in the fitting equation represents the sequential coding of corresponding months from 0 to 139.

\subsection{Spatial Distribution of Transition Dates}

The spatial distribution of transition dates from Segment 1 ("first big dry") to Segment 2 ("big wet") in Yunnan Province (Figure 4a) suggests that the onset date of "big wet" first appeared in July 2005 in the south part of Yunnan Province and occurred more than one year later in the northwest and north parts. In some grids in the east part of Yunnan, the drought states lasted for one additional month, until September 2006. The largest lag was 15 months, between east and south parts of Yunnan Province as the transition from "first big dry" to "big wet" occurred. The transition dates from Segment 2 ("big wet") to Segment 3 ("second big dry") were consistent in November 2008 in each part of Yunnan Province (not displayed here), suggesting that the period of "big wet" in the south part was more than one year longer than that in the northwest and northeast parts of Yunnan Province.

The spatial distribution of transition dates from Segment 3 ("second big dry") to Segment 4 ("fluctuating") (Figure 4b) reveals that the onset date of fluctuation first appeared in March 2010 in the northwest part of Yunnan Province, in August 2010 in the south part, and in September 2011 in the northeast part. These results imply that the arid status lasted more than a year longer in the northeast compared to the other parts of Yunnan Province. 

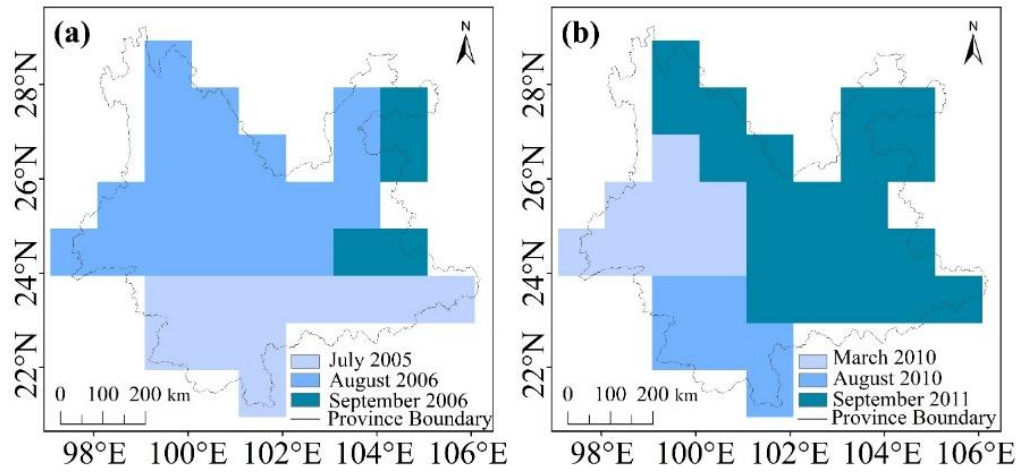

Figure 4. (a) Spatial distribution of transition dates from Segment 1 ("first big dry") to Segment 2 ("big wet"); (b) dates from Segment 3 ("second big dry") to Segment 4 of Total Water Storage Anomalies.

\subsection{Spatial Distribution of Trends of TWSA}

The TWSA trend in Segment 1 varied from -2.86 to $-0.79 \mathrm{~cm} /$ year, where the most severe decline in TWSA occurred in the south part of Yunnan Province (Figure 5a). The TWSA trend in Segment 2 varied from 2.52 to $4.58 \mathrm{~cm}$ /year, where TWSA recovered faster in the west and central parts than in the south part of Yunnan Province (Figure 5b). The total water loss in Segment 1 varied from 3.29 to $8.59 \mathrm{~cm}$, and the total water loss was larger in the west and southeast parts and less in the north part of Yunnan Province (Figure 5e). The total water gains in Segment 2 varied from 5.80 to $10.47 \mathrm{~cm}$, where the total water gains were larger in the southwest and central parts, but less in the north part of Yunnan Province (Figure 5f). The scatterplot (Figure 5i), showing the water losses in "first big dry" and water gains in "big wet", in each grid, suggests that all grids were above the 1:1 line. This indicates that the whole region had greater water gains than water losses during Segments 1 and 2. In other words, TWS rebounded over the initial level of the start date of Segment 1 at the end of the Segment 2.

TWSA rapidly decreased with a varying rate, from 0.74 to $8.01 \mathrm{~cm} /$ year, in Segment 3 (Figure 5c), while the most serious water loss occurred in the west and south parts and a weaker water loss occurred in other parts of Yunnan Province. The spatial patterns of total water loss during Segment 3 (Figure 5g) are similar to the patterns of decline trends of TWSA (Figure 5c). Combining all TWSA changes during Segments 1,2, and 3, the scatterplot of total water loss and total water gain of each grid in Yunnan Province (Figure 5j) suggests that all points were below the 1:1 line. This indicates that the total water storage was deficient in almost all grids from 2002 to the end of the "second big dry".

In segment 4, the spatial difference in the TWSA trend was large (Figure 5d) for the entire Yunnan Province, which varied from -0.37 to $2.83 \mathrm{~cm} /$ year. Correspondingly, the spatial patterns of total water storage changes varied greatly (Figure $5 \mathrm{~h}$ ), where losses mainly occurred in the west part and gains in the east part of Yunnan Province.

If we consider the whole study period, two distinct clusters can be identified from the scatterplot of total water gain and total water loss (Figure 5k). One cluster is above the 1:1 line, implying that water gains during the "big wet" were greater than the water losses. The second cluster is below the 1:1 line, which suggests that there were greater water losses than gains. We then identified the spatial patterns of the two clusters from the spatial distribution of the trend of total water gains to losses during the study period (Figure 5l) in Yunnan Province. It is interesting to note that all grids within the red circle in Figure 5k correspond to the red dots in Figure $5 \mathrm{l}$ and are located in the north and east parts of Yunnan Province. For these grids, the ratio of water gain to water loss was 2.21, indicating that the total water gains were more than twice as much total water loss in these regions. All grids within the green circle in Figure 5k correspond to the green dots in Figure 51 and are all located in the south and southwest parts of Yunnan Province. Here, the ratio of water gain to water loss was only 0.52 , which reveals that the total water gains were nearly half of the total water loss. These results 
imply that water storage recovers faster in the north and east parts, compared to other parts of Yunnan Province, which most likely has a longer effect on the TWSA in these different regions.
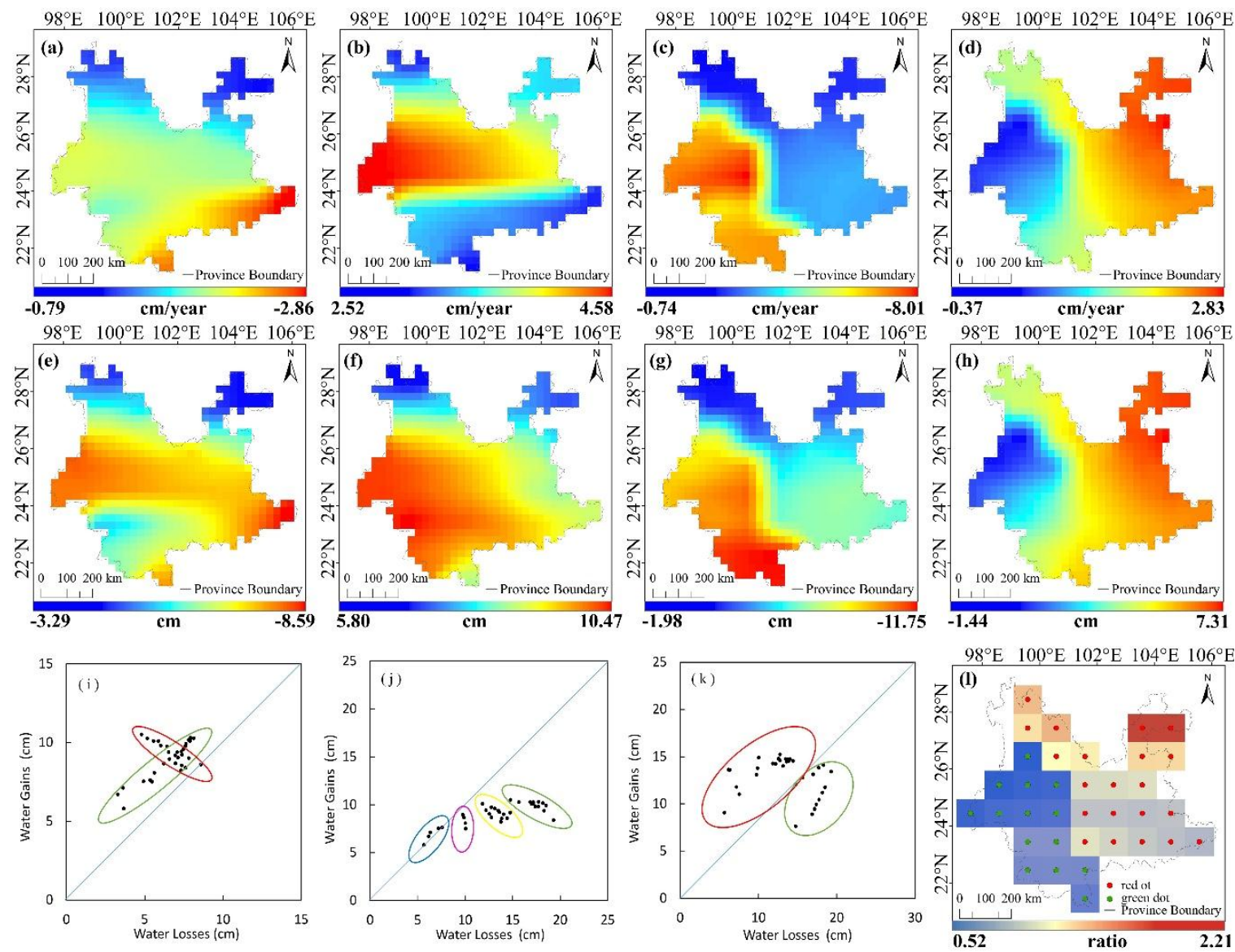

Figure 5. Spatial distribution of Total Water Storage Anomalies trends during (a) Segment 1; (b) Segment 2; (c) Segment 3; and (d) Segment 4; spatial distribution of total water storage changes during (e) Segment 1; (f) Segment 2; (g) Segment 3; and (h) Segment 4; scatterplot of total water gains vs water losses during (i) Segments 1 and 2; (j) Segments 1, 2, and 3; and (k) Segments 1, 2, 3, and 4; (l) spatial distribution of the ratio of total water gains to losses during the study period. The red dots correspond to the points clustered in the red circle in (k), and the green dots correspond to the points clustered in the green circle in $(\mathbf{k})$ of Yunnan province.

\subsection{Relationship between TWSA and CCI SMA}

TWSA and CCI SMA were calculated by subtracting the same baseline average from January 2007 to December 2014. The relationship between de-seasonalized CCI SMA and TWSA from 2007 to 2014 (Figure $6 \mathrm{~b}$ ) suggests that CCI SMA has a significant $(p=0.01)$ correlation with TWSA, with a correlation coefficient of 0.51 . This relationship further indicates that the variations in soil moisture are most likely one of the driving forces of variations in TWSA. The seasonal cycle of TWSA lagged SMA by about one month, which is consistent with results obtained by Rodell et al. [45]. In addition, the de-seasonalized TWSA and CCI SMA had similar patterns; for example, both TWSA and CCI SMA increased during 2009-2010 and decreased during 2010-2011. However, large differences between TWSA and CCI SMA were found in 2008, where TWSA had a peak and CCI SMA had a more complex fluctuating pattern (Figure 6b). 

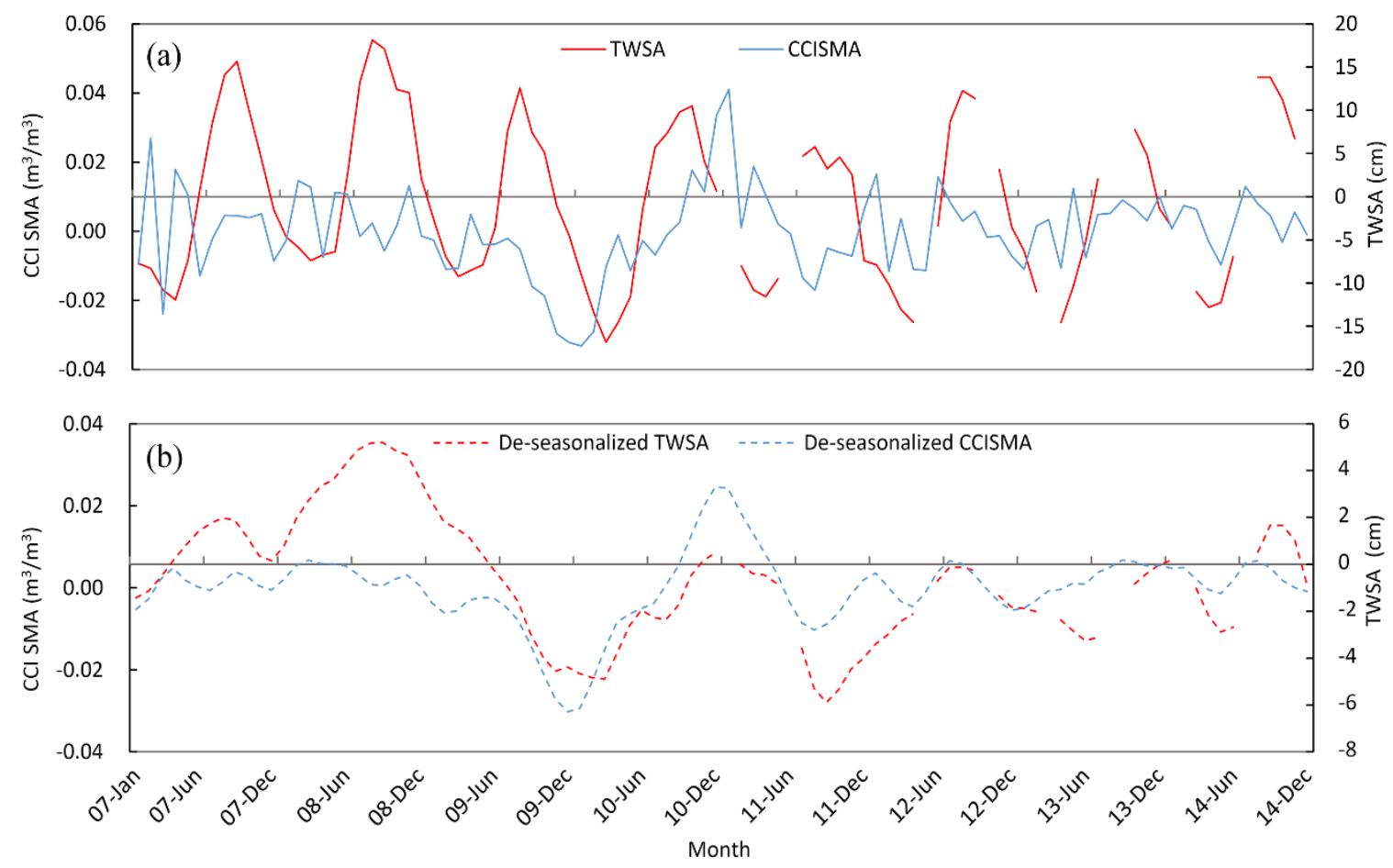

Figure 6. (a) Monthly average Total Water Storage Anomalies and Soil Moisture Anomalies from 2007 to 2014; the solid red line represents the de-seasonalized Total Water Storage Anomalies; the solid blue line represents the de-seasonalized Climate Change Initiative (CCI) Soil Moisture Anomalies. (b) Monthly average de-seasonalized and smoothed Total Water Storage Anomalies and Soil Moisture Anomalies from 2007 to 2014 in Yunnan Province. The month without data is vacant.

To further explore the differences between TWSA and CCI SMA, the spatial distribution of TWSA and CCI SMA at the tipping points in July 2008 (end of the "big wet"), December 2009 (end of the "second big dry"), August 2010, and November 2011 were analyzed (Figure 7). TWSA and SMA displayed the same spatial patterns in July 2008, with high values in all parts of Yunnan Province (Figure 7a,e, respectively), and similar spatial patterns occurred in August 2010 (Figure 7c,g). However, large differences were found in the spatial distribution of TWSA and SMA in December 2009 (Figure 7b,f), in which the minimum TWSA and CCI SMA occurred in all parts (Figure 7f) and in the central and east parts (Figure 7b) Yunnan Province, respectively. The reason for this difference may be related to the similar transit date of Segment 3. Differences were also noted in November 2011 (Figure 7d,h), where CCI SM gradually increased from the northwest to the southeast, while TWSA gradually increased from the northeast to the southwest. 

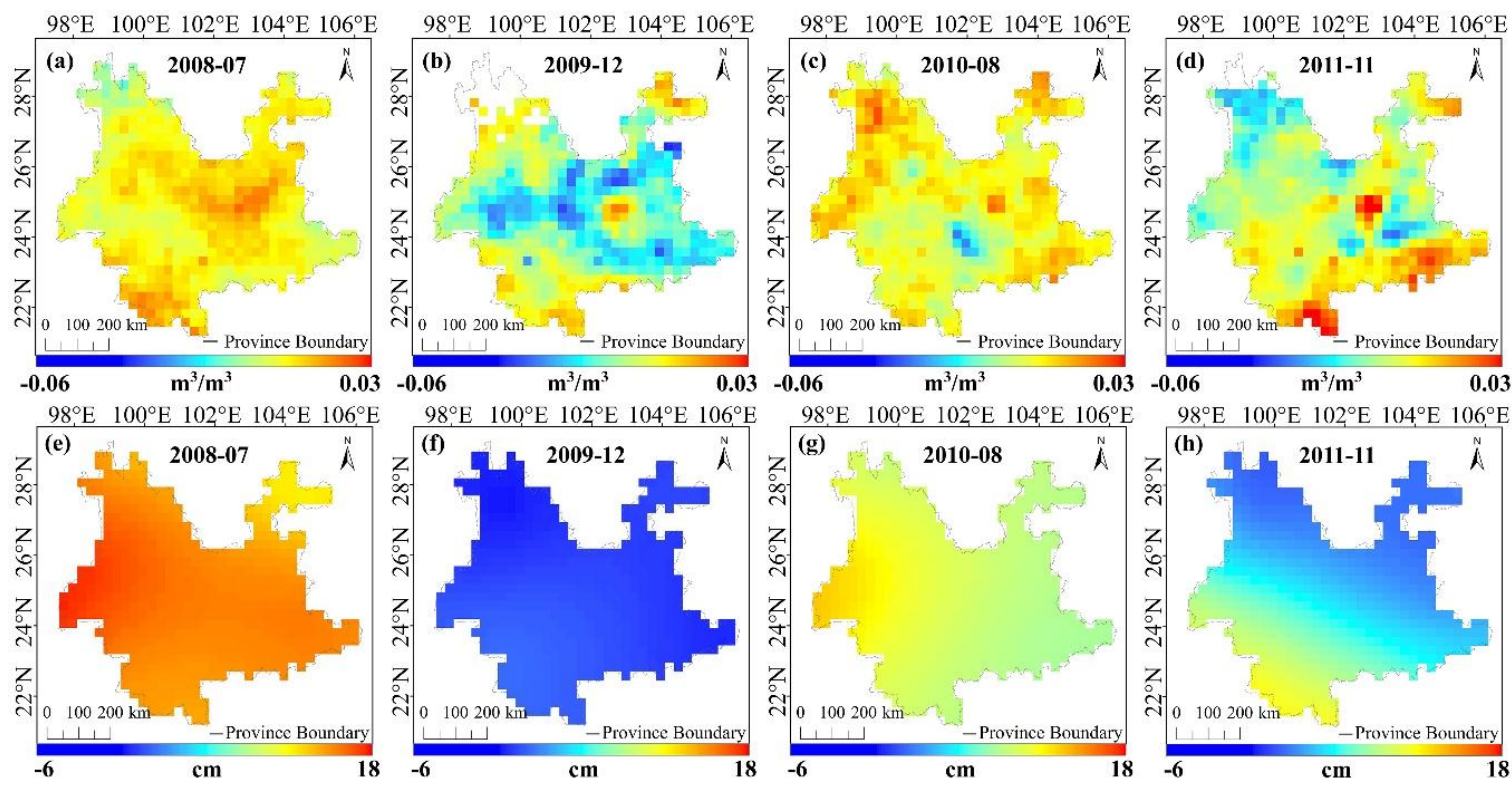

Figure 7. Spatial distribution of CCI Soil Moisture Anomalies (a-d) and Total Water Storage Anomalies (e-h) in July 2008 (end of the "big wet"), December 2009 (end of the "second big dry"), August 2010, and November 2011.

\section{Discussion}

\subsection{Drought Derived from Precipitation, CCI SMA and TWSA}

The time series for the monthly averaged de-seasonalized and smoothed TWSA, SMA, and precipitation (Figure 8a) suggests that both TWSA and SMA had abnormal minimum values during the drought period and can be used as a signal for drought. However, some differences were prominent in the drought phases for 1-2 months. The seasonal cycle of CCI SMA lagged precipitation by about one month, suggesting that less precipitation impacted soil moisture after 1 month. The seasonal cycle of TWSA lagged SMA by about one month, which suggests that the lag time between TWSA and precipitation is about 2 months. Therefore, precipitation is an acuminous signal, which reflects drought and decreases in the early stages of a drought when agriculture is minimally affected. Furthermore, CCI SM and TWSA are obtuse in response to drought, with reductions that reveal the direct impact of droughts on agriculture and water storage.

Good correspondence was noted between TWSA, CCI SMA, and meteorological drought in different drought grades (Figure 8b). From winter in 2009 to spring in 2010, October 2009 and February 2010 exhibited slight drought conditions, while December 2009 and January 2010 had a moderate drought. The persistent meteorological drought is consistent with the drought reflected by TWSA and CCI SM. However, the meteorological drought occurring in individual months did not lead to significant changes in TWS and CCI SM, indicating that the single-month meteorological drought may have had a less serious effect on soil moisture and water storage. These results suggest that the droughts described using CCI SMA and TWSA are more fit to represent the effects of droughts, especially on agriculture.

The significant correlation between CCI SMA and TWSA can be explained by two reasons. One explanation is that there are many large lakes located in Yunnan Province, where the largest nine lakes have areas of above $30 \mathrm{~km}^{2}$, a cumulative total area of about $1042 \mathrm{~km}^{2}$, and a water storage volume of about $302 \times 10^{8} \mathrm{~m}^{3}$ [46]. As soil moisture decreases during a drought, the inflow and storage capacity of lakes also decreases, which probably contributes to the reduction of total water storage. The second explanation is that the decrease in soil moisture directly contributes to the total water storage loss. 

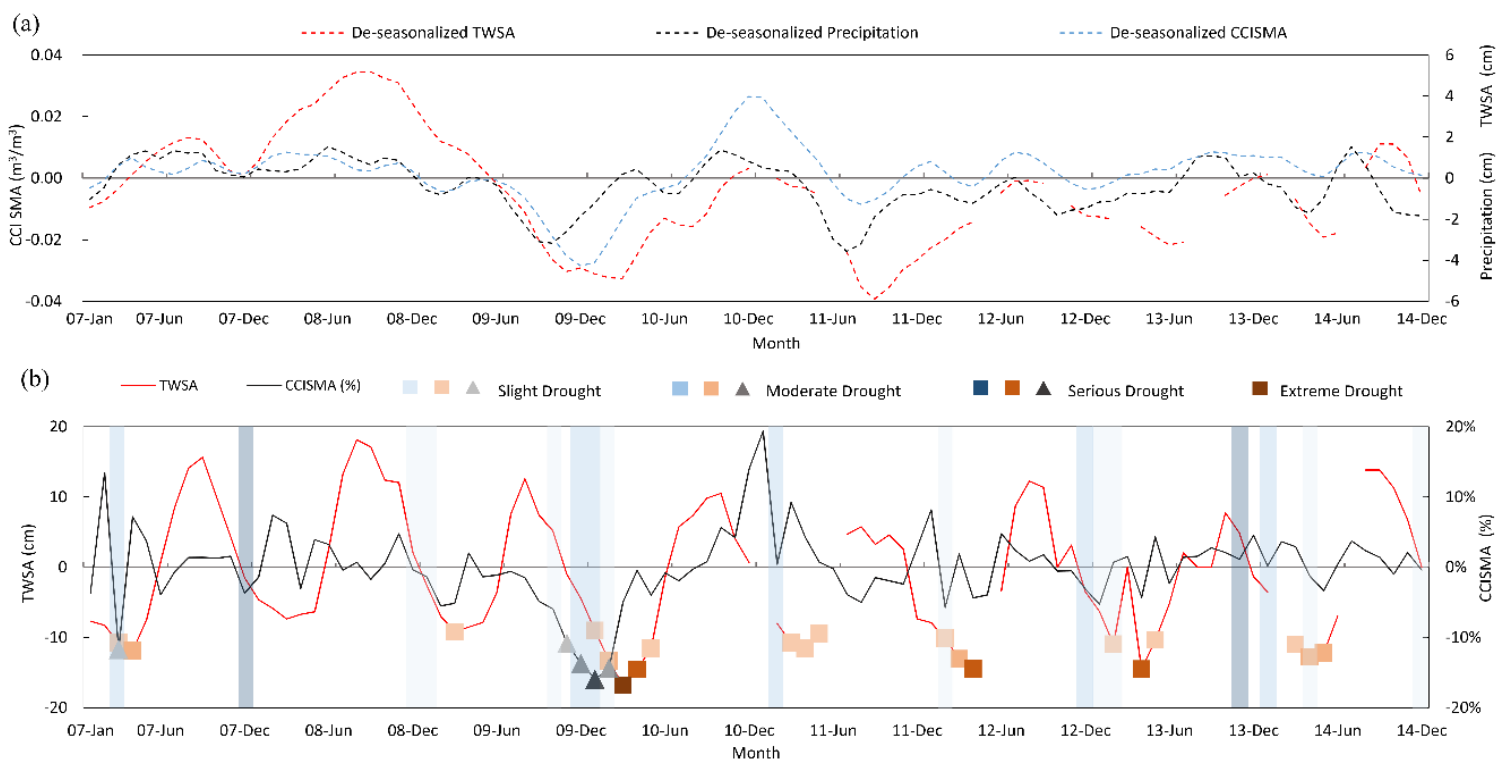

Figure 8. (a) Monthly average de-seasonalized and smoothed Total Water Storage Anomalies, Soil Moisture Anomalies, and precipitation anomalies, from 2007 to 2014, in Yunnan Province; (b) Drought grades were calculated by precipitation, Climate Change Initiative Soil Moisture (CCI SM), and Total Water Storage Anomalies (TWSA). The different blue bars represent the drought grades from precipitation. The month with no bar means non-drought. The red line represents TWSA and red squares represent the drought grades from TWSA. The gray line represents TWSA, and gray triangles represent the drought grades from CCI SM anomaly percentages.

\subsection{Contribution of SMA to TWSA}

Because in situ soil moisture data only covered Segment 3 completely, we calculated the loss ratio and duration of TWSA, CCI SM, and in situ soil moisture at three depths of Segment 3 (Table 1). It should be noted that the duration of Segment 3 for four data are different because the beginning and ending times of these four data in Segment 3 were inconsistent. The contribution of CCI SM and in situ SM at 10, 20, and $40 \mathrm{~cm}$ to TWSA were determined to be $2.32 \%, 7.21 \%, 20.55 \%$, and $41.94 \%$, respectively. The total contribution of SMA to TWSA in Segment 3 was about $42 \%$, which indicates that the variation in soil moisture only explains less than half of the total water storage change.

Table 1. Contributions of Soil Moisture Anomalies (SMA) to TWSA.

\begin{tabular}{|c|c|c|c|c|c|}
\hline \multirow{2}{*}{ Terms } & \multirow{2}{*}{ TWSA (cm) } & \multirow{2}{*}{$\operatorname{CCI~SM~}\left(\mathrm{m}^{3} / \mathrm{m}^{3}\right)$} & \multicolumn{3}{|c|}{ In Situ SM $\left(\mathrm{m}^{3} / \mathrm{m}^{3}\right)$} \\
\hline & & & $10 \mathrm{~cm}$ & $20 \mathrm{~cm}$ & $40 \mathrm{~cm}$ \\
\hline Ratio & -0.450 & -0.002 & -0.006 & -0.008 & -0.007 \\
\hline Duration (months) & 15 & 13 & 12 & 11 & 10 \\
\hline Total change & -6.750 & -0.031 & -0.066 & -0.091 & -0.073 \\
\hline Equivalent thickness (cm) & - & -0.157 & -0.330 & -0.91 & -1.46 \\
\hline Contribution rate & - & $2.32 \%$ & $7.21 \%$ & $20.55 \%$ & $41.94 \%$ \\
\hline
\end{tabular}

\section{Conclusions}

The spatial and temporal characteristics of TWSA in Yunnan Province were investigated, and droughts-derived from monthly precipitation, TWSA, and CCI SMA during 2007 to 2014-were compared. The following conclusions were made based off our results:

(1) The whole study period can be divided into four segments, including two water loss periods, one water gain period, and one fluctuating period, from 2002 to 2014. The water loss lasted 
one year longer in the north and east parts, than in other parts of Yunnan Province. The spatial patterns of TWSA trends at each segment varied greatly, indicating that drought evolution processes are complex. The west and south parts eventually lost more water, while the central, north and east parts received more water during the period from 2002 to 2014.

(2) There were significant correlations between CCI SMA and TWSA. The drought detected from CCI SMA had a one-month lag, while TWSA had a two-month lag, compared to the meteorological drought. Both the de-seasonalized TWSA and CCI SMA effectively captured and indicated early signs of droughts from 2009 to 2010 in Yunnan. Furthermore, the spatial patterns of CCI SMA and TWSA were found to be consistent as well, indicating that their grid products can be used to effectively analyze the spatial patterns of drought evolution processes, which is a weakness of in situ observations of soil moisture.

Acknowledgments: We wish to thank Zunyi Xie (University of Technology Sydney, Australia) for helpful suggestions on dealing with GRACE TWSA. This research was supported by Yunnan Social Development (2012CA021), China National Natural Science Foundation(41730751), and Special Trade Project for Commonweal of Water Resource (201401026).

Author Contributions: Siyu Ma carried out the study and wrote the manuscript. Qianxin Wu and Jie Wang participated in the design and revision of the manuscript. Shiqiang Zhang designed the study, gave suggestions on the analysis of the results, and revised the manuscript.

Conflicts of Interest: The authors declare no conflict of interest.

\section{References}

1. Wilhite, D.A. Drought as a natural hazard: Concepts and definitions. Drought A Glob. Assess. 2000, 1, 3-18.

2. Wang, A.; Lettenmaier, D.P.; Sheffield, J. Soil moisture drought in China, 1950-2006. J. Clim. 2011, 24, 3257-3271. [CrossRef]

3. Damberg, L.; Aghakouchak, A. Global trends and patterns of drought from space. Theor. Appl. Climatol. 2014, 117, 441-448. [CrossRef]

4. Jiménez Cisneros, B.E.; Oki, T.; Arnell, N.W.; Benito, G.; Cogley, J.G.; Döll, P.; Jiang, T.; Mwakalila, S.S. Freshwater Resources in Climate Change 2014: Impacts, Adaptation, and Vulnerability, Part A: Global and Sectoral Aspects; Contribution of Working Group II to the Fifth Assessment Report of the Intergovernmental Panel on Climate Change; Cambridge University Press: Cambridge, UK, 2014; pp. 229-269.

5. Huang, J.; Yu, H.; Guan, X.; Wang, G.; Guo, R. Accelerated dryland expansion under climate change. Nat. Clim. Chang. 2016, 6, 166-171. [CrossRef]

6. Huang, J.; Yu, H.; Dai, A.; Wei, Y.; Kang, L. Drylands face potential threat under $2{ }^{\circ} \mathrm{C}$ global warming target. Nat. Clim. Chang. 2017, 7, 417-422. [CrossRef]

7. Qiu, J. China drought highlights future climate threats. Nature 2010, 465, 142-143. [CrossRef] [PubMed]

8. Zhang, Q.; Yu, Z.G.; Xu, C.Y.; Anh, V. Multifractal analysis of measure representation of flood/drought grade series in the Yangtze Delta, China, during the past millennium and their fractal model simulation. Int. J. Climatol. 2010, 30, 450-457. [CrossRef]

9. Zhang, Q.; Jing, T.; Chen, Y.Q.; Chen, X.H. Changing properties of hydrological extremes in south China: Natural variations or human influences? Hydrol. Process. 2010, 24, 1421-1432. [CrossRef]

10. Long, D.; Shen, Y.; Sun, A.; Hong, Y.; Longuevergne, L.; Yang, Y.; Li, B.; Chen, L. Drought and flood monitoring for a large karst plateau in southwest China using extended GRACE data. Remote Sens. Environ. 2014, 155, 145-160. [CrossRef]

11. Xu, K.; Yang, D.; Xu, X.; Lei, H. Copula based drought frequency analysis considering the spatio-temporal variability in southwest China. J. Hydrol. 2015, 527, 630-640. [CrossRef]

12. Heim, R.R.J. A review of twentieth-century drought indices used in the united states. Bull. Am. Meteorol. Soc. 2002, 83, 1149-1165.

13. Tigkas, D.; Vangelis, H.; Tsakiris, G. Drinc: A software for drought analysis based on drought indices. Earth Sci. Inf. 2015, 8, 697-709. [CrossRef]

14. Heim, R.R.J. Drought indices: A review. In Drought: A Global Assessment; Wilhite, D.A., Ed.; Routledge: Abingdon, UK, 2000; pp. 159-267. 
15. Mckee, T.B.; Doesken, N.J.; Kleist, J. The relationship of drought frequency and duration to time scales. In Proceedings of the 8th Conference on Applied Climatology, Anaheim, CA, USA, 17-22 January 1993; pp. 179-184.

16. Mckee, T.B.; Doeskin, N.J.; Kleist, J. Drought monitoring with multiple time scales. In Proceedings of the 9th AMS Conference on Applied Climatology, Dallas, TX, USA, 15-20 January 1995; pp. 233-236.

17. Ma, X.; Li, N.; Xie, Y.; Hong, C.C.; Guo, T.; Guan, L.; Xu, H.; Zhang, Q.; Tao, Q. Relationships between soil moisture and precipitation and study on assessment techniques of resist droughts. Chin. Agric. Sci. Bull. 2014, 30, 193-198.

18. Hollinger, S.E.; Isard, S.A.; Welford, M.R. A new soil moisture drought index for predicting crop yields. In Proceedings of the 8th Conference on Applied Climatology, Anaheim, CA, USA, 17-22 January 1993; pp. 187-190.

19. Owe, M.; Jeu, R.D.; Holmes, T. Multisensor historical climatology of satellite-derived global land surface moisture. J. Geophys. Res. Earth Surf. 2008, 113, 196-199. [CrossRef]

20. Wagner, W.; Lemoine, G.; Rott, H. A method for estimating soil moisture from ers scatterometer and soil data. Remote Sens. Environ. 1999, 70, 191-207. [CrossRef]

21. Naeimi, V.; Scipal, K.; Bartalis, Z.; Hasenauer, S.; Wagner, W. An improved soil moisture retrieval algorithm for ERS and METOP scatterometer observations. IEEE Trans. Geosci. Remote Sens. 2009, 47, 1999-2013. [CrossRef]

22. Kerr, Y.H.; Waldteufel, P.; Wigneron, J.P.; Martinuzzi, J.; Font, J.; Berger, M. Soil moisture retrieval from space: The Soil Moisture and Ocean Salinity (SMOS) mission. IEEE Trans. Geosci. Remote Sens. 2002, 39, 1729-1735. [CrossRef]

23. Liu, Y.Y. Developing an improved soil moisture dataset by blending passive and active microwave satellite-based retrievals. Hydrol. Earth Syst. Sci. 2011, 15, 425-436. [CrossRef]

24. Liu, Y.Y.; Dorigo, W.A.; Parinussa, R.M.; Jeu, R.A.M.D.; Wagner, W.; Mccabe, M.F.; Evans, J.P.; Van Dijk, A.I.J.M. Trend-preserving blending of passive and active microwave soil moisture retrievals. Remote Sens. Environ. 2012, 123, 280-297. [CrossRef]

25. Wagner, W.; Dorigo, W.; De Jeu, R.; Fernandez, D.; Benveniste, J.; Haas, E.; Ertl, M. Fusion of active and passive microwave observations to create an essential climate variable data record on soil moisture. ISPRS Ann. 2012, I-7, 315-321.

26. Dorigo, W.A.; Gruber, A.; Jeu, R.A.M.D.; Wagner, W.; Stacke, T.; Loew, A.; Albergel, C.; Brocca, L.; Chung, D.; Parinussa, R.M. Evaluation of the ESA CCI soil moisture product using ground-based observations. Remote Sens. Environ. 2015, 162, 380-395. [CrossRef]

27. Peng, J.; Niesel, J.; Loew, A.; Zhang, S.Q.; Wang, J. Evaluation of satellite and reanalysis soil moisture products over southwest China using ground-based measurements. Remote Sens. 2015, 7, 15729-15747. [CrossRef]

28. Syed, T.H.; Famiglietti, J.S.; Rodell, M.; Chen, J.; Wilson, C.R. Analysis of terrestrial water storage changes from GRACE and GLDAS. Water Resour. Res. 2008, 44, 339-356. [CrossRef]

29. Tangdamrongsub, N.; Steeledunne, S.C.; Gunter, B.C.; Ditmar, P.G.; Weerts, A.H. Data assimilation of GRACE terrestrial water storage estimates into a regional hydrological model of the Rhine River basin. Hydrol. Earth Syst. Sci. 2015, 19, 2079-2100. [CrossRef]

30. Jin, S.; Zhang, T. Terrestrial water storage anomalies associated with drought in southwestern USA from GPS observations. Surv. Geophys. 2016, 37, 1-18. [CrossRef]

31. Yirdaw, S.Z.; Snelgrove, K.R.; Agboma, C.O. GRACE satellite observations of terrestrial moisture changes for drought characterization in the Canadian prairie. J. Hydrol. 2008, 356, 84-92. [CrossRef]

32. Chen, J.L.; Wilson, C.R.; Tapley, B.D.; Longuevergne, L.; Yang, Z.L.; Scanlon, B.R. Recent La Plata basin drought conditions observed by satellite gravimetry. J. Geophys.Res. Atmos. 2010, 115, 1842-1851. [CrossRef]

33. Houborg, R.; Rodell, M.; Li, B.; Reichle, R.; Zaitchik, B.F. Drought indicators based on model-assimilated Gravity Recovery and Climate Experiment (GRACE) terrestrial water storage observations. Water Resour. Res. 2012, 48, 2515-2521. [CrossRef]

34. Xie, Z.Y.; Huete, A.; Restrepo-Coupe, N.; Ma, X.L.; Devadas, R.; Caprarelli, G. Spatial partitioning and temporal evolution of Australia's total water storage under extreme hydroclimatic impacts. Remote Sens. Environ. 2016, 183, 43-52. [CrossRef] 
35. Li, Y.G.; He, D.; Hu, J.M.; Cao, J. Variability of extreme precipitation over Yunnan Province, China 1960-2012. Int. J. Climatol. 2015, 35, 245-258. [CrossRef]

36. Wang, L.P.; Wang, S.F.; Zhang, L.D.; Wang, F.l.; Long, X.M. Spatial-temporal characteristics of precipitation in Yunnan Province from 1960 to 2013. Water Resour. Power 2016, 34, 20-24.

37. Swenson, S.; Wahr, J. Post-processing removal of correlated errors in GRACE data. Geophys. Res. Lett. 2006, 33, 2006. [CrossRef]

38. Landerer, F.W.; Swenson, S.C. Accuracy of scaled GRACE terrestrial water storage estimates. Water Resour. Res. 2012, 48, 4531. [CrossRef]

39. Sakumura, C.; Bettadpur, S.; Bruinsma, S. Ensemble prediction and intercomparison analysis of GRACE time-variable gravity field models. Geophys. Res. Lett. 2014, 41, 1389-1397. [CrossRef]

40. National Meteorological Information Center of the China Meteorological Administration (CMA). Available online: http:/ / data.cma.cn/ (accessed on 1 July 2017).

41. China Meteorological Administration. Classification of Meteorological Drought; Standards Press of China: Beijing, China, 2006.

42. Gardner, E. Forecasting: Methods and applications (second edition). J. Forecast. 1984, 3, 457-460. [CrossRef]

43. Fisher, R. On the "probable error" of a coefficient of correlation deduced from a small sample. Metron 1921, 1, 3-32.

44. Owe, M.; Van de Griend, A.A. Comparison of soil moisture penetration depths for several bare soils at two microwave frequencies and implications for remote sensing. Water Resour. Res. 1998, 34, 2319-2327. [CrossRef]

45. Rodell, M.; Velicogna, I.; Famiglietti, J.S. Satellite-based estimates of groundwater depletion in India. Nature 2009, 460, 999. [CrossRef] [PubMed]

46. Chong, D.; Li, H.J.; Fan, S.; Li, J.J.; Wang, J.; Zhang, S.Q. Inversion of chlorophyll-a concentration in nine plateau lakes in Yunnan based on MODIS data. Chin. J. Ecol. 2017, 36, 277-286.

(c) 2017 by the authors. Licensee MDPI, Basel, Switzerland. This article is an open access article distributed under the terms and conditions of the Creative Commons Attribution (CC BY) license (http:/ / creativecommons.org/licenses/by/4.0/). 